\title{
A Model with Leaf Area Index and Trunk Diameter for LoRaWAN Radio Propagation in Eastern China Mixed Forest
}

\author{
Yin Wu ${ }^{D},{ }^{1}$ Genwei Guo, ${ }^{1}$ Guiyun Tian, ${ }^{2}$ and Wenbo Liu $^{3}$ \\ ${ }^{1}$ College of Information Science and Technology, Nanjing Forestry University, No. 159, LongPan Road, Nanjing 210037, China \\ ${ }^{2}$ School of Engineering, Newcastle University, Newcastle upon Tyne NE1 7RU, UK \\ ${ }^{3}$ College of Automation, Nanjing University of Aeronautics and Astronautics, No. 29, JiangJun Avenue, Nanjing 211106, China
}

Correspondence should be addressed to Yin Wu; wuyin@njfu.edu.cn

Received 18 September 2019; Revised 26 May 2020; Accepted 3 June 2020; Published 22 June 2020

Academic Editor: Yuan Li

Copyright (c) 2020 Yin Wu et al. This is an open access article distributed under the Creative Commons Attribution License, which permits unrestricted use, distribution, and reproduction in any medium, provided the original work is properly cited.

\begin{abstract}
Internet of Things (IoT) is a very promising technology in forest engineering, especially for the environment and plant growth monitoring. LoRa Wide Area Network (LoRaWAN) is a prevailing choice for the Forestry IoT owing to its low-power and longrange ability. Real-world deployment and network optimization require accurate path-loss modeling, so the LoRaWAN radio channel in the forest is needed to be intensively studied. However, most of the subsistent propagation models do not involve specific forestry environmental parameters. In this paper, two parameters related with the trees are considered: the leaf area index and the tree trunk diameter. Due to the time-changing characteristics of these two items (from spring to winter), an empirical model has been developed through extensive measurement campaigns: Firstly, the channel measurement platform is designed based on a real scene of mixed forest. Secondly, the fading characteristics of the channel transmission for LoRa nodes are tested, and the corresponding model is presented and evaluated. Lastly, an energy harvesting LoRaWAN is deployed and operated in a sampled forest region of Eastern China for environment monitoring based on our propagation model. The results show that $433 \mathrm{MHz}$ LoRa path loss in the mingled forest could be precisely predicted by our proposed model. Moreover, network coverage and energy consumption optimization of the LoRa nodes could be performed, which enables the perpetual development of reliable forestry evolution monitoring system.
\end{abstract}

\section{Introduction}

The multispecies forest is an important silvicultural regime for sustainable forest management. Due to its vertical stratification structure, canopy plasticity, and niche separation, the mixed forest could utilize canopy space more efficiently to improve forest productivity and nutrient cycle more effectively than the natural forest. Along with its increasing area, mixed forest management faces different challenges [1]: competitions for natural resources of different tree species, different tending measures of growth stages, and improving pest control technologies. So it is urgent to develop and exploit reasonable resource monitoring systems for the prediction and management of mixed forest $[2,3]$. Low-power wide-area networks (LPWANs) are a promising technology because of their high applicability, low energy consumption, and self-organizing mechanism. An overview and comparison of different emerging LPWAN technologies have been presented in [4-6] and listed in Table 1. In particular, LoRaWAN is one of the most prospective LPWAN technologies, gaining greater interest from the research and industrial communities. It has also been increasingly adopted in the Internet of Things (IoT) in the forest [7-10].

LoRaWAN links every node via wireless communication, just as Figure 1 shows. When they are deployed in the forest, the radio signal may experience attenuation as a result of diffraction, reflection, scattering, and absorption effects caused by various obstacles of trees and shrub. Mixed forests are challenging radio propagation environments, and there is a need to understand better the propagation characteristics in order to design efficient wireless systems that can operate inside them. However, the modeling of forest radio propaga- 
TABLE 1: Comparison of LPWAN technologies.

\begin{tabular}{|c|c|c|c|c|c|}
\hline & LoRa & NB-IoT & Sigfox & ZigBee & WiFi \\
\hline Frequency & $\begin{array}{c}868 \mathrm{MHz} \text { (EU); } \\
915 \mathrm{MHz} \text { (USA); } \\
433 \mathrm{MHz} \text { (Asia) }\end{array}$ & $\begin{array}{l}\text { Depends on } \\
\text { the frequency } \\
\text { licensed to LTE }\end{array}$ & $\begin{array}{c}868 \mathrm{MHz}(\mathrm{EU}) ; \\
915 \mathrm{MHz} \text { (USA); } \\
433 \mathrm{MHz} \text { (Asia) }\end{array}$ & $\begin{array}{c}868 \mathrm{MHz}(\mathrm{EU}) ; \\
915 \mathrm{MHz} \text { (USA); } \\
433 \mathrm{MHz} \text { (Asia); } \\
2.4 \mathrm{GHz}\end{array}$ & $\begin{array}{c}2.4 \mathrm{GHz} \text { and } \\
5 \mathrm{GHz}\end{array}$ \\
\hline Transmission distance & $\begin{array}{l}\text { Long }(1-2 \mathrm{~km} \text { in urban, } \\
20 \mathrm{~km} \text { in rural })\end{array}$ & Long (10 km in rural) & Long (40 km in rural) & Short (10-100 m) & Short $(50-100 \mathrm{~m})$ \\
\hline Data transfer rate & $0.3-50 \mathrm{kbps}$ & $160 \mathrm{kbps}-250 \mathrm{kbps}$ & $100 \mathrm{bps}$ & $250 \mathrm{kbps}$ & $2.4 \mathrm{Gbps}$ \\
\hline Theoretical battery life & 10 years/AA battery & 10 years/AA battery & 10 years/AA battery & 1 year/AA battery & 1 year/AA battery \\
\hline Network delay & $1 \mathrm{sec}-3 \mathrm{sec}$ & $6 \mathrm{sec}-10 \mathrm{sec}$ & $20 \mathrm{sec}-25 \mathrm{sec}$ & Less than $1 \mathrm{sec}$ & Less than $1 \mathrm{sec}$ \\
\hline Networking mode & Gateway-based & $\begin{array}{c}\text { Telecommunication } \\
\text { operator-based }\end{array}$ & Gateway-based & Gateway-based & Gateway-based \\
\hline
\end{tabular}

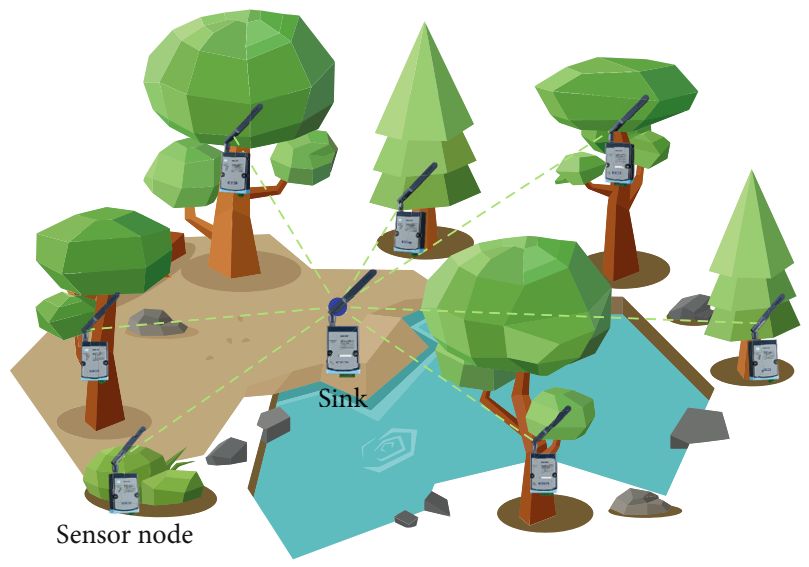

FIgURE 1: The diagram of LoRaWAN in a mixed forest.

tion is relatively complicated as different environmental parameters (such as type of vegetation, density, height of trees, and weather conditions) can have strong effects.

Researchers have developed several well-known empirical models to study the radio channel characteristics in the forest: Meng et al. performed experimental path loss modeling for a near ground radio wave propagation in a plantation at 240 and $700 \mathrm{MHz}$ over a large forest depth [11], the proposed LITU-R mode mainly considers the lateral wave effect and shows better performance for the prediction of foliage loss over a large foliage depth (up to $5 \mathrm{~km}$ ). Azevedo et al. found that the signal attenuation is dependent on the vegetation density, defined by the product of the tree density and the average diameter of the trunks [12]. Anderson et al. presented the results of a UWB measurement campaign and comprehensive parametric analysis for four different forest densities across multiple diverse locations in Maryland of Virginia. They demonstrated that UWB propagation in a forest environment heavily depends on the forest density, antenna type, and forest configuration [13]. Palaios et al. studied the near-ground propagation characteristics in a typical central European forest in UHF-bands around $485 \mathrm{MHz}$ [14]; the result showed that the forest type has a significant effect to the propagation and thus mixed-type of forest requires its own model.
On the other hand, the characterization of the LoRa radio channel also got few achievements recently: Benaissa et al. studied LoRa path loss and temporal fading $(868 \mathrm{MHz})$ for dairy cows in barns [15]. Hosseinzadeh et al. assessed the indoor propagation performance of LoRa technology and identified the model that best describes the process [16]. El Chall et al. investigated the LoRaWAN radio channel in both indoor and outdoor environments at urban and rural locations in Lebanon [17]. Sanchez-Iborra et al. presented a comprehensive performance evaluation of LoRaWAN under different environmental conditions [18]. A point-to-point LoRa path loss characterization has been researched in the urban, forest, and coastal environment [19]. Especially Sardar et al. analyzed some environmental factors in the forestry LoRa communication such as different antenna heights and packet lengths [20].

Based on the above literature, we find that most of the existing empirical models concentrated on single species of trees such as cedars and pines. Small Acacia confusa or cryptomeria, glass, and shrub wood were rarely taken into account, much less the mixed forest. Secondly, most models are based on the radio frequency and transmission distance, while the environmental parameters were scarcely considered. The prior models mainly divided the trees into in-leaf and out-of-leaf situations. However, the leaf area of trees changes with different seasons, and the cross-sectional area of tree trunk would also influence the radio propagation in its growth stage. Thirdly, the randomly distributed trees in a mixed forest are spatially different from the artificially planted trees that are arranged in rows and columns, whereas sub-GHz LoRa for this kind of forest has not yet been investigated up to now. Finally, since on-field measuring devices are always energy-constrained, it is likely that novel energyharvesting (EH) IoT technologies will find their use in the forest monitoring [21-23]. So to combine the energyefficient radio transmission power control mechanism with the accurate propagation model would be essential and inevitable for the EH-wireless sensor system in the forest.

In this work, practical LoRaWAN sensor nodes are used to characterize the path loss effect at $433 \mathrm{MHz}$ band in the mingle forest environment at different heights from the ground. The measurement result which compared with the Okumura-Hata-Rural path loss model [24] and the LITU-R 


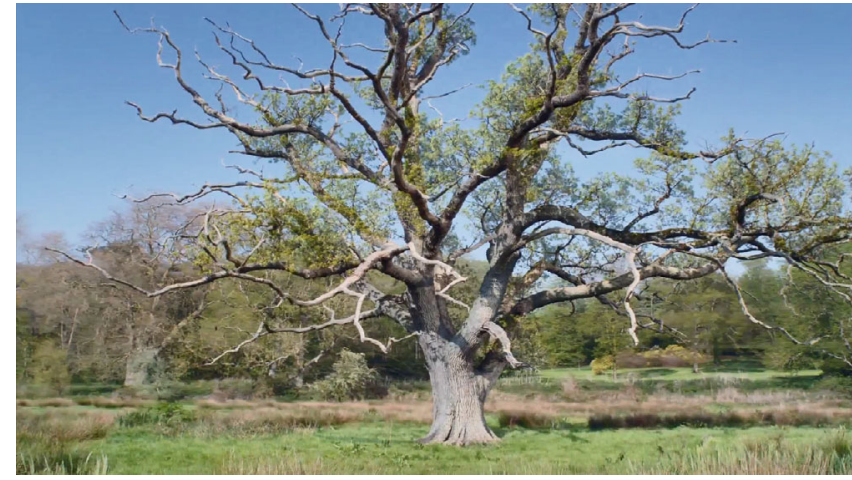

(a) Spring

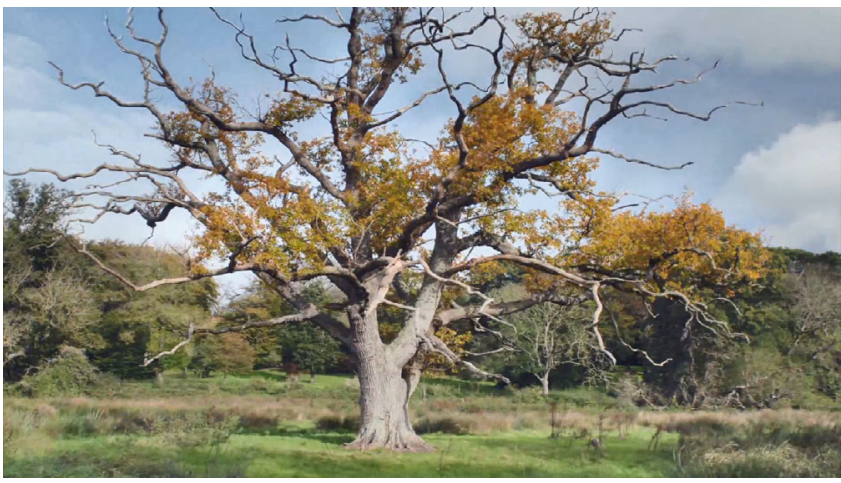

(c) Autumn

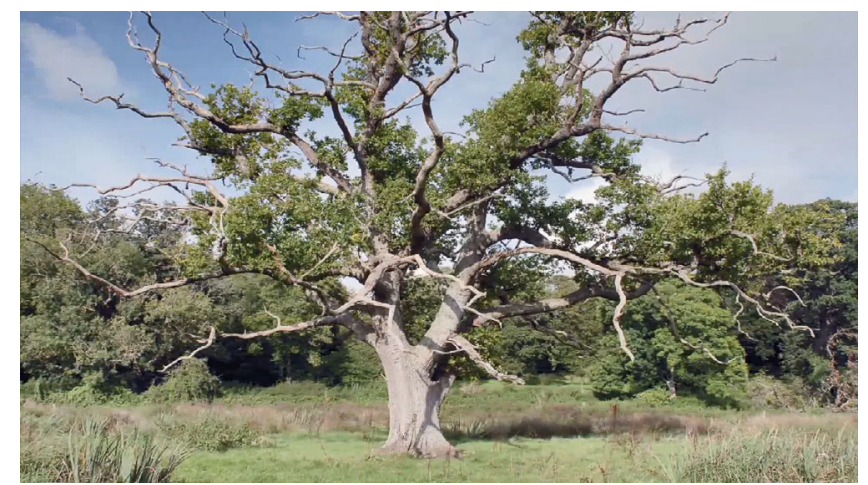

(b) Summer

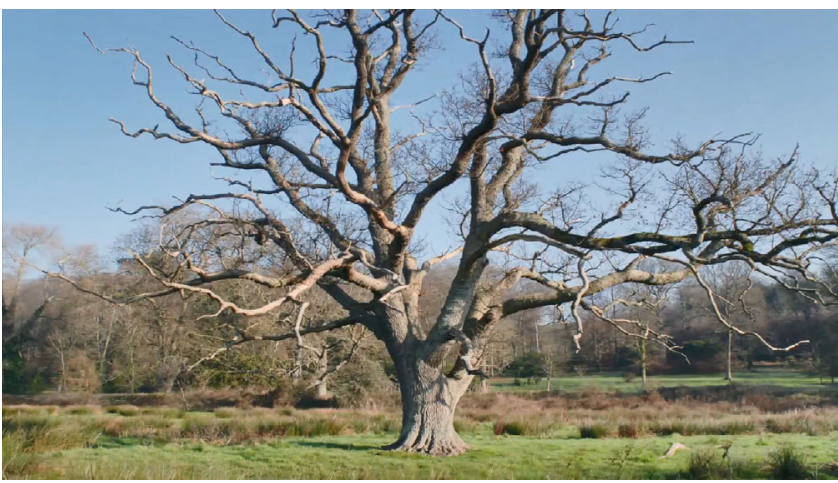

(d) Winter

Figure 2: The variation of the same tree at four different growth stages in the sample forest.

model [11] shows a significant difference. Hence, the Leaf Area Index (LAI) that can reflect the density of leaves at different growth stages is introduced as one characteristic parameter, and the trunk Diameter at Breast Height (DBH) that represents cross-section area of trees as the other. An empirical model comprising these two new parameters is then developed, and we compared it with the existing models to demonstrate its accuracy among the LoRaWAN nodes deployed in a mixed forest district in Nanjing city of Eastern China. The measured data, as well as the developed path loss models, can be used for efficient planning and deployment of EH-WSN in mixed forest environments. To the best of our knowledge, this is the first study on the analysis of propagation characteristics of LoRa in a mixed forest.

The rest of this paper is organized as follows: Section 2 describes the measurement campaign and presents the practical sensor nodes used and the investigated scenarios. Data analysis and model construction are discussed in Section 3. Section 4 tests the proposed model in a real field and compares it with existing models. Conclusions and future studies are given in Section 5.

\section{Experimental Setup and Measurement Campaign}

2.1. Mixed Forest Environment Description. We hold the modeling procedure at one typical mixed forest in Nanjing Forestry University, Jiangsu Province, Eastern China $\left(118^{\circ} 48^{\prime} 55.98^{\prime \prime} \mathrm{E}, 32^{\circ} 04^{\prime} 59.01^{\prime \prime} \mathrm{N}\right)$. This demonstration forest base was built in 1999 and has a length of $300 \mathrm{~m}$ and a width of $200 \mathrm{~m}$. Pinus massoniana, Ilex chinensis, Quercus variabilis, Lindera glauca, Photinia beauverdiana, and Rubus corchorifolius were the dominant variety with an average crown of approximately $2.75 \mathrm{~m}$. The plants were approximately $1.3-11.9 \mathrm{~m}$ high with trunk $\mathrm{DBH}$ of approximately $0.11-0.56 \mathrm{~m}$.

The modeling measurement was mainly carried out at four growth stages including spring germination stage, summer leaf expanding stage, autumn leaf falling stage, and winter senescence stage in 2018. A variation of the same tree at the four growth stages is shown in Figure 2: In early March, the tree came up and had sparse leaves (Figure 2(a)); next, the leaves grew rapidly in late June (Figure 2(b)); and the LAI and DBH also reached the peak value; then the tree was in leaf falling stage by September (Figure 2(c)); finally, the leaves faded away and only branches existed in Winter (Figure 2(d)). These different morphological characteristics could definitely affect the wireless signal propagation that passed through and nearby.

2.2. Measurement Devices. The experimental platform used in our measurement campaigns is depicted in Figure 3. An Arduino UNO with Dragino LoRa shield expansion board was used as the sensor node, powered by a $3.7 \mathrm{~V}$, $3000 \mathrm{mAH}$ rechargeable lithium battery [25]. It has an integrated LoRa SX1278 transceiver and runs LoRaWAN protocol. One node without associated sensors that connected to a 


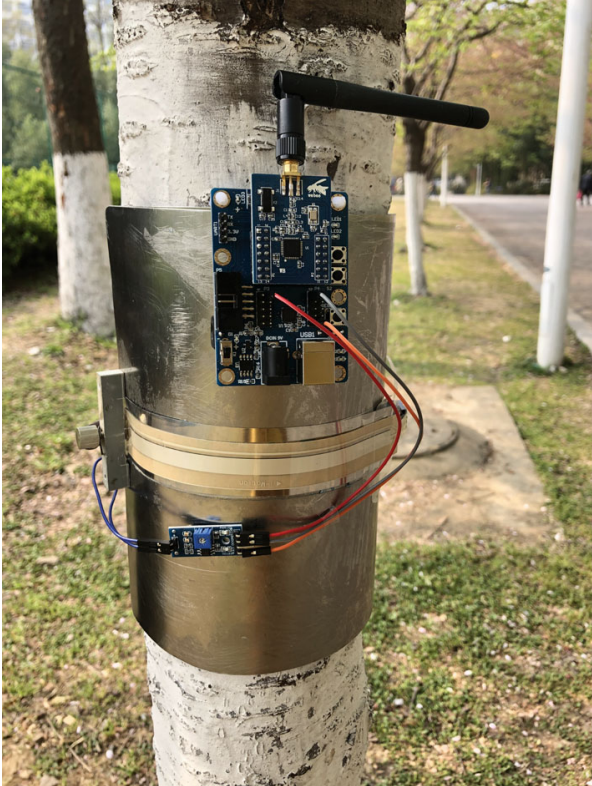

(a) DBH LoRa node

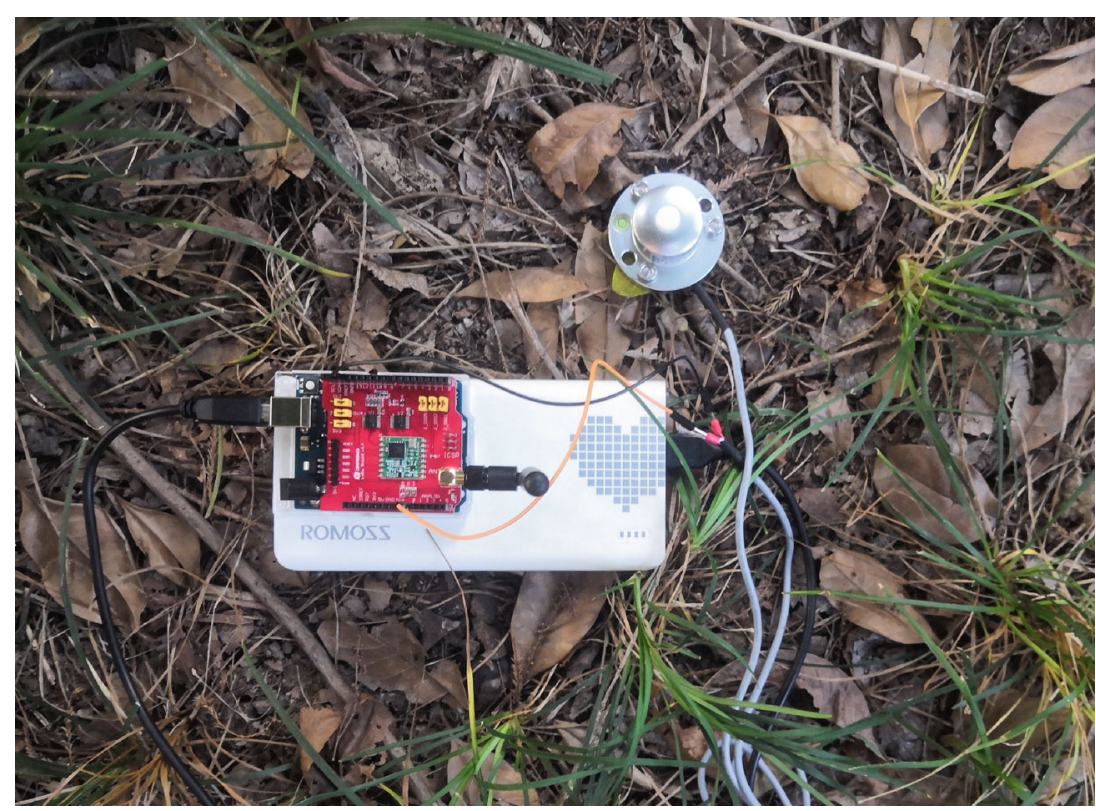

(b) PAR LoRa node

FIgURE 3: The DBH and PAR sensor node amounted in trees.

laptop was used as the sink, and it was able to receive LoRa frames from -20 to $-141 \mathrm{dBm}$ depending on the LoRa BW and SF [26]. Both sink and sensor nodes used an omnidirectional dipole antenna of $3 \mathrm{dBi}$ gain. Upon the reception of each frame, the sink provided the received signal strength indicator (RSSI), the signal-to-noise ratio (SNR), and the payload message. These received parameters were recorded on the server side on the laptop for further analysis and processing. The quality of reception can be monitored in realtime with an MQTT Web client application.

The LoRa nodes were configured to send a packet every interval. The packets also included a sequential number in order to identify the packet loss. The transmit power was set to $14 \mathrm{dBm}$, SF to 12 (to achieve the best receiver sensitivity), and the BW to $125 \mathrm{kHz}$, using the three default channels $(433.175,433.375$, and $433.575 \mathrm{MHz})$. The packet payload was 37 bytes including 13 bytes MAC header. The measurement setup parameters are listed in Table 2. During all the measurements, the position of the sink was fixed, whereas the sensor nodes could be moved to different locations.

As can be seen from Figure 3, there were two particular designed forestry sensors: $\mathrm{DBH}$ and Photosynthetically Active Radiation (PAR). The DBH sensor mainly consisted of a high accuracy sliding film potentiometer, a circular flexible elastic wheel rim, a fixed position deck, and a signal processing bridge circuit. After tightened installation onto the tree trunk, the potentiometer's slider could point out the exact value of its resistance, with which we can deduce the $\mathrm{DBH}$. The PAR sensor was designed for the measurement of LAI, which was based on the reference system [27, 28], it included two parts: the testing components and the reference component. The testing PAR sensors should be placed around the crown to measure the luminous flux which passed through, where the reference sensor could be set up in a clear field to provide contrast and evaluation. Both kinds of sen-
TABle 2: Measurement setup parameters.

\begin{tabular}{lc}
\hline Parameter & Value \\
\hline Sensor node & SX1278 \\
Sink & LG01-P, Dragino IoT kit \\
TX power & $14 \mathrm{dBm}$ \\
Frequency & $433 \mathrm{MHz}$ \\
Bandwidth (BW) & $125 \mathrm{KHz}$ \\
Antenna & $3 \mathrm{dBi}$ omnidirectional \\
Spreading factor (SF) & 12 \\
Coding rate & $4 / 5$ \\
Payload length & $37 \mathrm{bytes}$ \\
Time interval & $10 \mathrm{sec}$ \\
Sensor node antenna height & $0.5 \mathrm{~m}, 1.3 \mathrm{~m}, 2.0 \mathrm{~m}, 2.5 \mathrm{~m}, 3.0 \mathrm{~m}$ \\
Sink antenna height & $1.3 \mathrm{~m}$ \\
\hline
\end{tabular}

sors make up an effective and indispensable supply to the proposed radio propagation analysis of IoT in the forest.

2.3. Practical Measurement Setup. Throughout the experiments, the intention was to place the sink node at the center of designated deployment field and collect RSS readings at eleven different distances (i.e., 5, 10, 20, 30, 40, 50, 60, 70, 80,90 , and 100 meters) and along twelve different 30 degrees separated radials. Therefore, an area of $200 \mathrm{~m} \times 200 \mathrm{~m}$ is ideally needed to carry out the real field deployment experiment.

The antenna of the sink node was placed $1.3 \mathrm{~m}$ above the ground, i.e., height of DBH. RSSIs were then measured by the transmitting node with 5 heights from bottom to top at heights of $0.5,1.3,2,2.5$, and $3 \mathrm{~m}$. The transmitting and receiving antenna were maintained erect in all of the tests. The top and side views of the measurement site are shown 


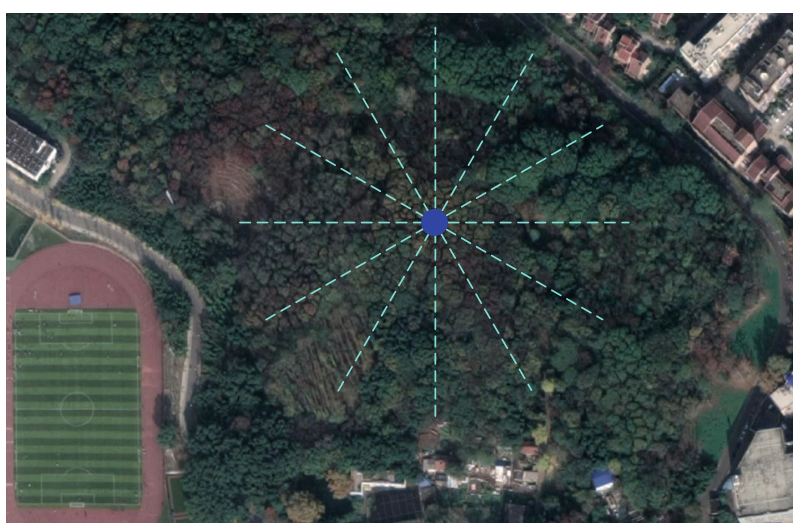

(a) Vertical top view

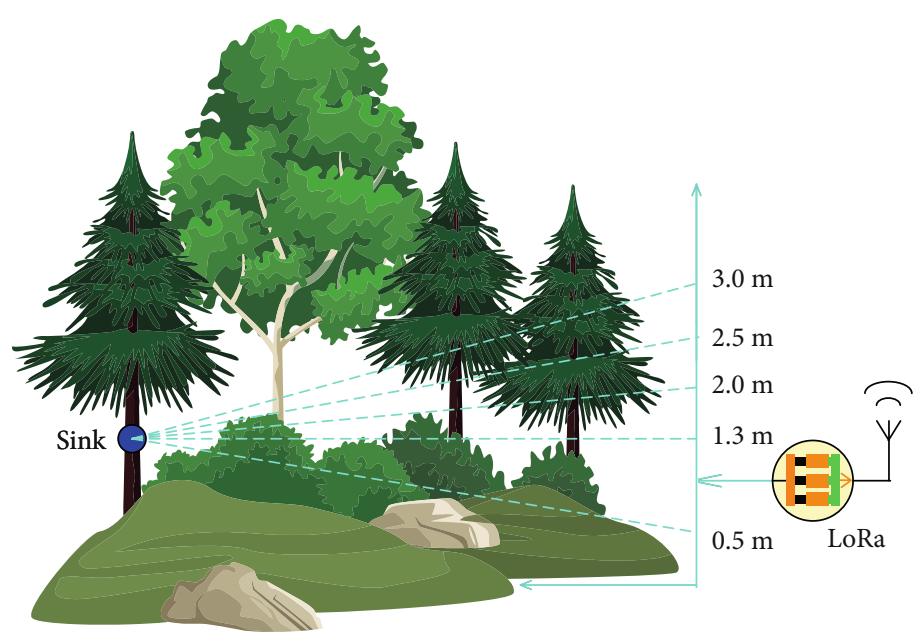

(b) Side view

Figure 4: Measurement site: the dashed lines represent the testing points, while the center dot is the sink.

in Figure 4. Note that as a result of extensive randomly scattered leaves, branches and bushes, the signal strength may change considerably even when there is a little variation in the position of transmitting antenna. So for each measurement point, 100 samples were collected, providing a sufficiently large dataset for approximating important statistical properties of the signal, such as mean and variability. Hence, the RF measurement of every 660 measuring point is an average of each 100 RSSI samples.

Besides, DBH and LAI results have also been collected and stored in the laptop which is connected with the sink. These two kinds of dedicated sensor nodes sent their data once a day to the sink for subsequent data analysis. They were all mounted on some specific trees selected by forest cultivation criterion [29]. We have held up the whole measurement campaign in four growth stages of the mixed forest once each; the average LAI and DBH values of the selected trees were used as the exact novel parameters in the next path loss model analysis.

\section{Measurement Results and Empirical Model}

In this section, we present the results of measurements conducted in the sample Mixed Forest of Nanjing Forestry University as described in Section 2. Then, we derive Pass Loss (PL) models from four different environments (spring, summer, august, and winter). At last, the proposed PL model is analyzed and discussed.

The RSSI values collected in the mixed forest environment were all converted into PL values which represent the signal attenuation on the path between the transmitter and the receiver antennas. As for the PL, value is a unique property of the transmission environment. Generally, the relationship between PL, transmission power, and RSSI is given as:

$$
\mathrm{PL}[\mathrm{dB}]=P_{T}[\mathrm{dBm}]-P_{R}[\mathrm{dBm}]+G_{T}[\mathrm{~dB}]+G_{R}[\mathrm{~dB}],
$$

where $P L$ refers to the path loss, $P_{T}$ refers to the transmitting power, $P_{R}$ is the receiving power $\left(P_{R}=\mathrm{RSSI}+\mathrm{SNR}\right)$, $G_{T}$ is the transmit antenna gain, and $G_{R}$ is the receive antenna gain. Table 3 just presents the PL results in the spring stage measurement when transmitting node's height is $0.5 \mathrm{~m}$.

Then, we calculate the average PL values related to each testing point including the very corresponding 5 heights. Figure 5 illustrates the average PL values versus the log of distance. Moreover, it illustrates the corresponding linear regression model lines.

It can be clearly pointed out that the variations among PL values which at the same distances are relatively large. In the mixed forest environment, such variations mainly occur as a result of the absence of Light of Sight communication between the transmitter and receiver, resulting in great signal fluctuation. In some instances, multiple waves of the transmitted signal may arrive at the sink, causing multipath fading. In other instances, only a small scattered portion of the transmitted signal may be received. Meanwhile, the season changes of mixed forest have a great influence on the PL values, the growth, and decay of branches and leaves directly transform the transmission routes of LoRaWAN.

Also, we can see that the average PL values closely follow the linear regression line, which indicates a dependency between the PL values and the log of distance. As a matter of fact, the linear regression provided in Figure 5 produces a reliable coefficient of determination (i.e., $0.8913<\mathrm{R}^{2}<$ 0.985 ), so the log-normal model is suitable for estimating the PL:

$$
\mathrm{PL}_{\mathrm{LN}}(\mathrm{dB})=\mathrm{PL}\left(d_{0}\right)+10 n \log _{10}\left(\frac{d}{d_{0}}\right)+X_{\sigma},
$$

where $n$ is the path loss exponent that indicates the rate at which the signal attenuates with the distance, $\operatorname{PL}\left(d_{0}\right)$ is the 
TABLE 3: Path loss measurement result $(\mathrm{dB})$ in the spring stage with transmitting height $0.5 \mathrm{~m}$.

\begin{tabular}{lcccccccccccc}
\hline Radial no. & Degree & $5 \mathrm{~m}$ & $10 \mathrm{~m}$ & $20 \mathrm{~m}$ & $30 \mathrm{~m}$ & $40 \mathrm{~m}$ & $50 \mathrm{~m}$ & $60 \mathrm{~m}$ & $70 \mathrm{~m}$ & $80 \mathrm{~m}$ & $90 \mathrm{~m}$ & $100 \mathrm{~m}$ \\
\hline 1 & 0 & 54.5 & 60.1 & 78.6 & 81.9 & 84.2 & 90.5 & 89.8 & 101.3 & 105.4 & 110.7 & 115.0 \\
2 & 30 & 52.2 & 64.3 & 82.1 & 85.2 & 81.7 & 93.2 & 97.3 & 97.1 & 110.5 & 112.2 & 118.3 \\
3 & 60 & 55.1 & 66.9 & 75.3 & 79.7 & 86.9 & 94.1 & 98.8 & 95.6 & 112.4 & 123.8 & 109.9 \\
4 & 90 & 56.9 & 68.2 & 73.7 & 83.8 & 88.2 & 97.7 & 96.9 & 103.4 & 107.6 & 121.1 & 117.1 \\
5 & 120 & 49.8 & 69.5 & 79.9 & 89.7 & 78.4 & 86.9 & 85.4 & 106.8 & 103.2 & 126.7 & 114.6 \\
6 & 150 & 51.6 & 63.3 & 83.5 & 86.5 & 82.5 & 88.1 & 88.7 & 109.7 & 99.3 & 117.5 & 107.3 \\
7 & 180 & 56.9 & 59.2 & 85.4 & 83.4 & 89.6 & 89.4 & 99.4 & 103.5 & 98.8 & 111.2 & 109.7 \\
8 & 210 & 59.3 & 65.7 & 89.1 & 90.3 & 92.3 & 92.5 & 98.5 & 101.9 & 104.7 & 107.5 & 119.2 \\
9 & 240 & 53.6 & 67.8 & 80.6 & 84.9 & 85.1 & 85.8 & 91.0 & 97.6 & 108.1 & 106.4 & 110.8 \\
10 & 270 & 48.8 & 62.6 & 77.2 & 81.1 & 86.8 & 94.3 & 94.7 & 93.4 & 102.6 & 109.3 & 133.5 \\
11 & 300 & 55.2 & 70.3 & 79.8 & 88.3 & 88.9 & 93.6 & 93.9 & 108.2 & 104.9 & 104.6 & 128.4 \\
12 & 330 & 58.4 & 64.8 & 78.4 & 82.6 & 84.6 & 87.7 & 95.5 & 110.1 & 103.8 & 109.9 & 116.7 \\
\hline
\end{tabular}

path loss at a known reference distance $d_{0}$ in the far-field, $X_{\sigma}$ denotes a zero-mean Gaussian random variable with standard deviation $\sigma$, which reflects the variation of the received power around the average.

Figure 6 shows the variations of attenuation index $n$ and PL $\left(d_{0}\right)$ according to different heights. For the heights above $1.3 \mathrm{~m}, n$ increases along with the height, especially when in the summer time, it is very reasonable due to the lush branches and leaves. The communication path always passes through the crown when the height is over $2 \mathrm{~m}$. However, the attenuation of $0.5 \mathrm{~m}$ is more or less larger than the $1.3 \mathrm{~m}$ except for the winter stage, we mainly attribute the phenomena to the bushes and thick undergrowth of the mixed forest. PL $\left(d_{0}\right)$ shows the opposite trends as the testing nodes' height increase, the values decline mostly because of the obstructions between transmitter, and receiver increase simultaneously. Furthermore, according to the different seasons, these two curves show a similar variation tendency, which we should thoroughly analyze. In other words, we may try to combine specific forest parameters together.

Here, we record the average $\mathrm{DBH}$ and LAI values with respect to the distance between transmitting nodes and sink. These two particular sensor nodes were located halfrandomly based on the forestry cultivation rules [29]. We can see that the average $\mathrm{DBH}$ values almost keep the same from spring to summer, then it has a rapid growth until winter in Figure 7(a). However, Figure 7(b) shows that the LAI values mainly change along with the seasons, while not with the distance. The two items could perfectly represent the characteristic of the sample mixed forest.

The last parameter of the log-normal model, represented by $X_{\sigma}$, can be defined by the standard deviation. Figure 5 reveals that a good approximation of the values can be obtained by using the mean. Here, we considered that $X_{\sigma}=$ $6.94 \mathrm{~dB}$.

So to precisely evaluate the parameters $n$ and $\mathrm{PL}\left(d_{0}\right)$, we introduce joint polynomials to combine the $\mathrm{DBH}$ and LAI together. The formulae that are shown below elaborate the three constants of the linear fitting $\left(x_{n 1}, x_{n 2}, x_{n 3}\right)$ with distance $\left(d_{M}\right.$, from sender to receiver) and height ( $h_{G}$, nodes' vertical position above the ground). These parameters were determined by curve fitting of the above Figures 6 and 7:

$$
\begin{aligned}
n & =x_{n 1} \cdot \Phi+x_{n 2}, \\
\Phi & =x_{n 3} \cdot\left[10 \cdot \log _{10}\left(V_{\mathrm{DBH}}-8.63\right)+V_{\mathrm{LAI}}\right], \\
x_{n 3} & =0.036 \cdot\left(d_{M}-24\right)^{0.61}, \\
x_{n 2} & =-0.5169 \cdot h_{G}{ }^{2}+2.9773 \cdot h_{G}+1.485, \\
x_{n 1} & =-0.0931 \cdot h_{G}{ }^{2}+0.8575 \cdot h_{G}-0.04392 .
\end{aligned}
$$

Similarly, we can have:

$$
\begin{aligned}
\mathrm{PL}\left(d_{0}\right) & =x_{\mathrm{PL} 1} \cdot \Psi+x_{\mathrm{PL} 2}, \\
\Psi & =x_{\mathrm{PL} 3} \cdot\left[\log _{10}\left(V_{\mathrm{DBH}}-V_{\mathrm{LAI}}\right)\right] \\
x_{\mathrm{PL} 3} & =0.045 \cdot d_{M}+0.32, \\
x_{\mathrm{PL} 2} & =41.8 \\
x_{\mathrm{PL} 1} & =-5.1856 \cdot h_{G} .
\end{aligned}
$$

$V_{\text {DBH }}$ and $V_{\text {LAI }}$ are just the values of DBH and LAI. Thus, a new empirical model could be created by using equations $((3)-(12))$ to estimate the LoRaWAN path loss in a typical mixed forest.

\section{Evaluation and Discussion}

4.1. Model Validation. We carried out the experimental evaluation at a different mixed forest in Eastern China's Nanjing city in 2019, it is located at the west side of $\mathrm{Zi}$ Jin Shan Mountain and has a length of $170 \mathrm{~m}$ and a width of $120 \mathrm{~m}$. The tree species structure is similar with our modeling forest, except for the heavy brush approximate $0.6 \mathrm{~m}$ high. Also, the $\mathrm{DBH}$ and LAI values are higher due to the well-protected natural environment.

The testing method was similar to that in the modeling experiments. Here, the validation measurement was executed 


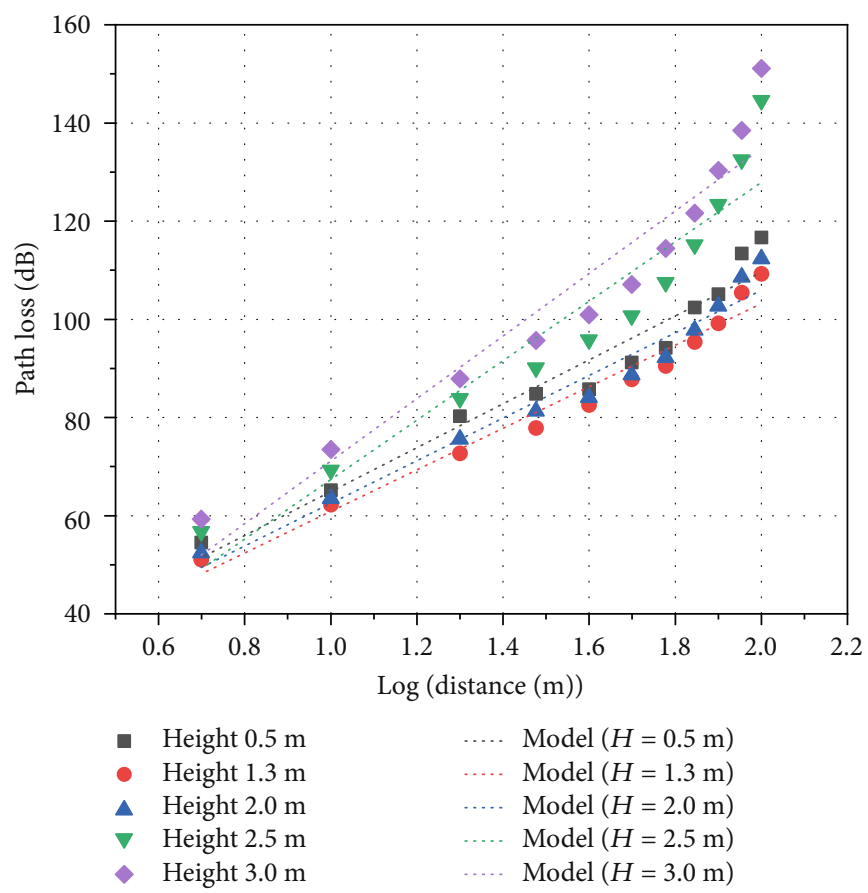

(a) Spring stage

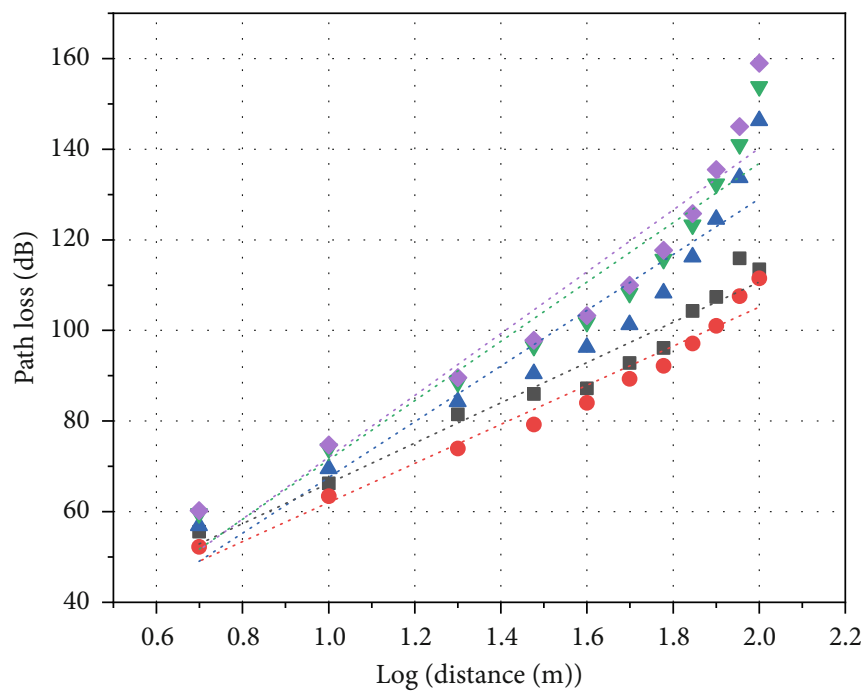
- Height $0.5 \mathrm{~m}$
- Height $1.3 \mathrm{~m}$
Model $(H=0.5 \mathrm{~m})$
- Height $2.0 \mathrm{~m}$ Model $(H=1.3 \mathrm{~m})$
v Height $2.5 \mathrm{~m}$
Model $(H=2.0 \mathrm{~m})$
- Height $3.0 \mathrm{~m}$
Model $(H=2.5 \mathrm{~m})$
Model $(H=3.0 \mathrm{~m})$

(b) Summer stage

Figure 5: Continued. 


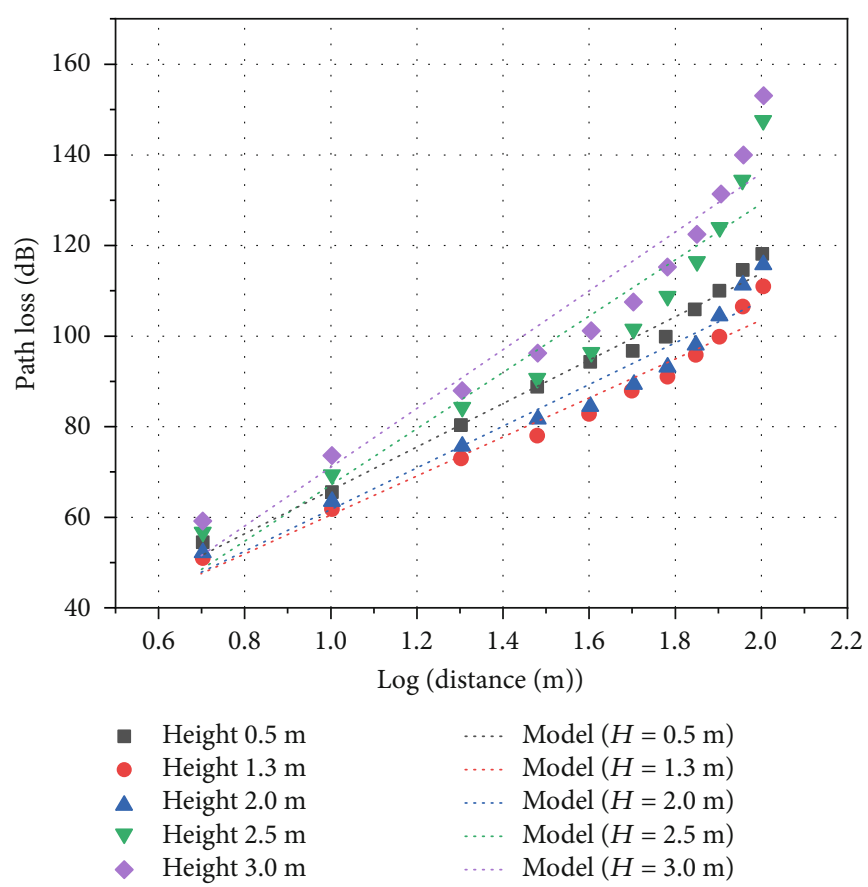

(c) August stage

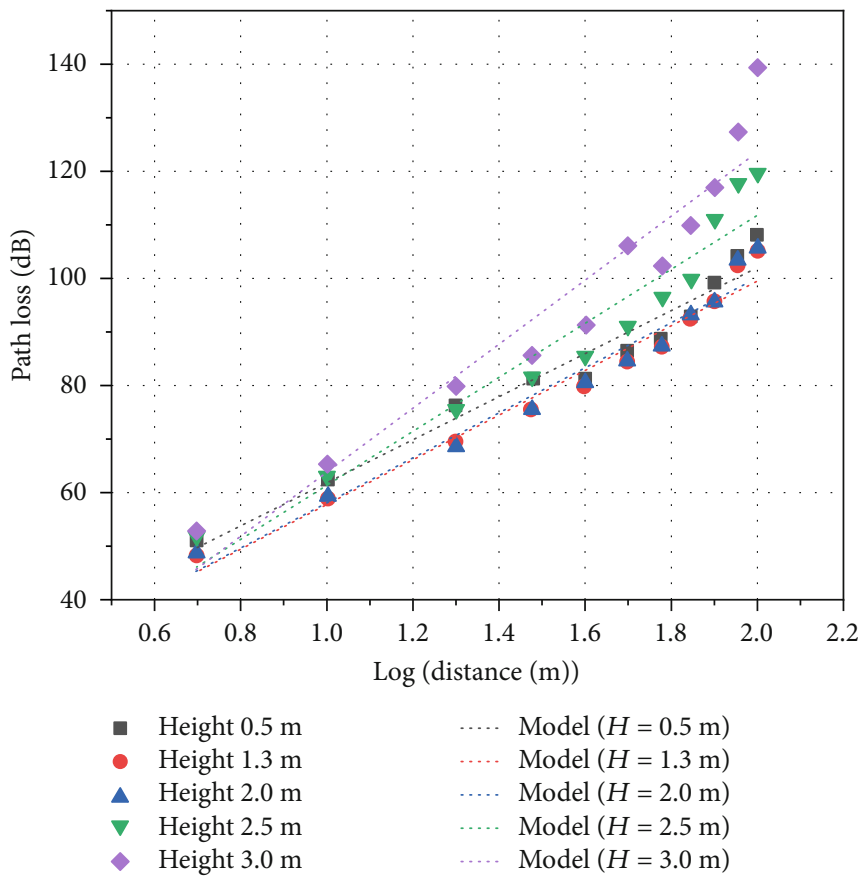

(d) Winter stage

FIGURE 5: Average path loss and linear regression lines for the four-stage environments.

at 5 different heights $(0.75 \mathrm{~m}, 1.3 \mathrm{~m}, 1.75 \mathrm{~m}, 2.25 \mathrm{~m}$, and $2.75 \mathrm{~m}$ ) along one straight line between the transmitter and receiver. On the same time, two forestry parameters (LAI and DBH) at each validation point could be collected conveniently. So we implemented the whole validation from March to July, and the testing positions were chosen with an extensive representativeness for different growth stages as much as possible.
The comparison of measurement results and the proposed new model is shown below in Figure 8. 95\% of the $R^{2}$ values are larger than 0.85 , the least value being 0.81 . Most of the Root Mean Square Error (RMSE) values were between 2 and 4 , as shown in Table 4.

We can see from the results that the proposed model matches the measurements quite well. In general, the presence of high density of trees can lead to a bad quality 


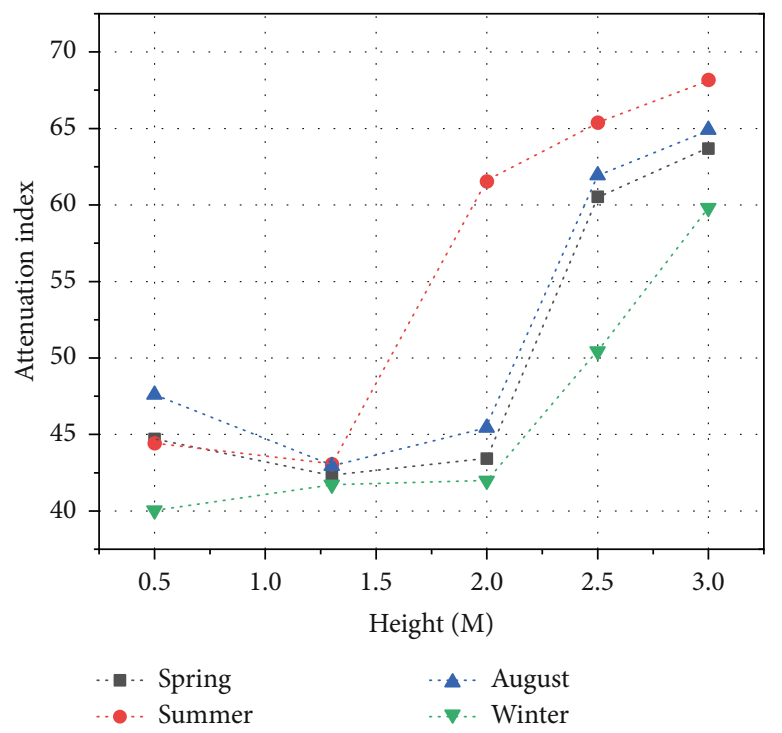

(a)

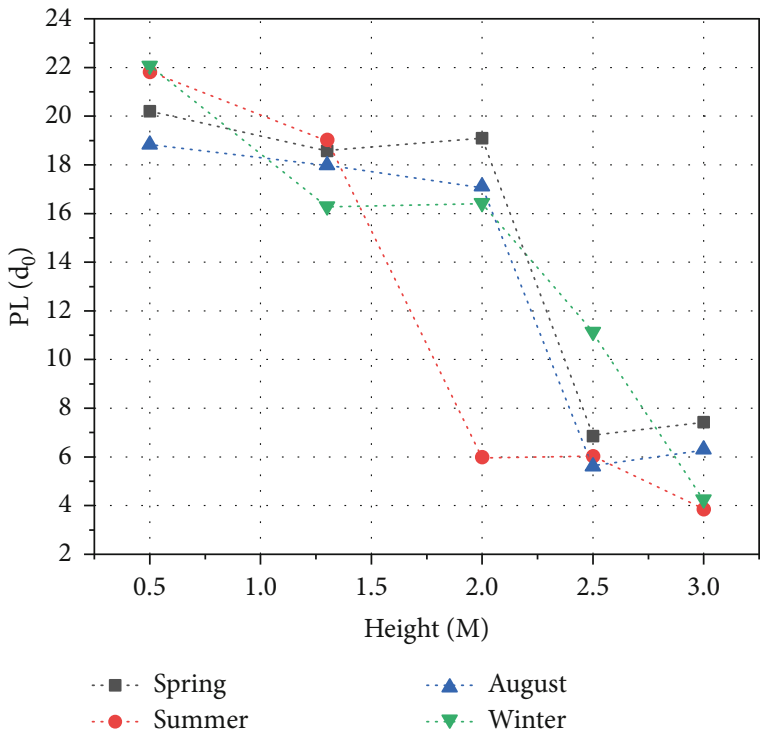

(b)

Figure 6: Average attenuation index $n$ and $\mathrm{PL}\left(d_{0}\right)$ of the four-stage environments.

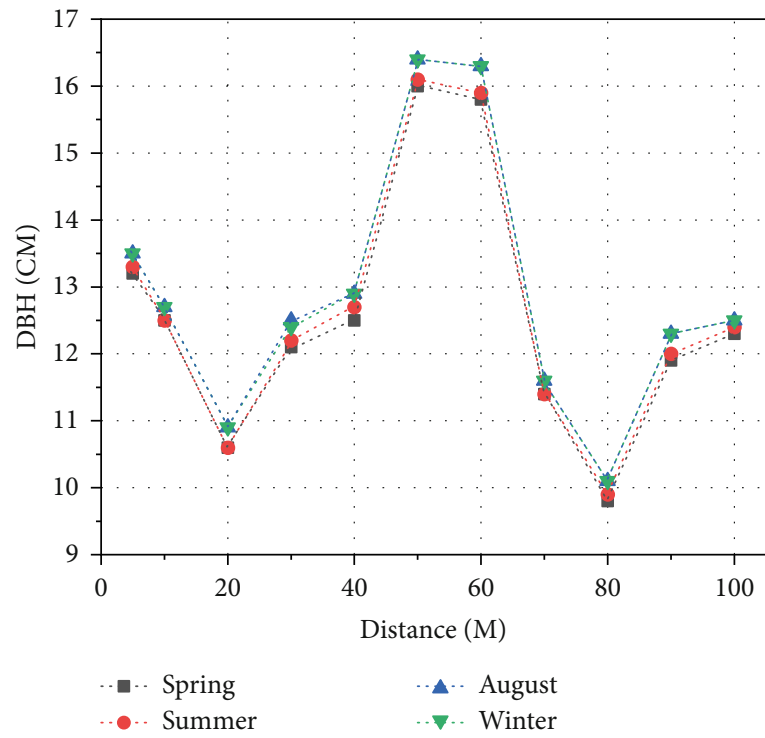

(a)

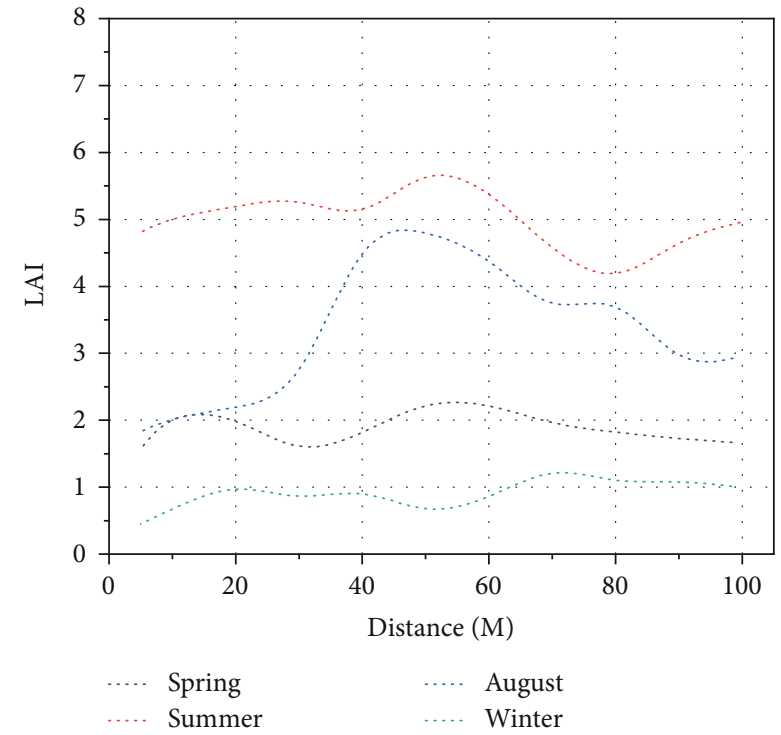

(b)

Figure 7: Average DBH and LAI of the four-stage environments.

reception: the higher value of LAI and DBH always means that there are more obstructions of radio scattering, reflections, diffractions, and absorptions. Hence, this nonline of sight PL values increase sharply along with the transmission distance and antenna height.

Then, the proposed new model has also been compared with some existing models at testing point (d), as shown in Figure 9: The results for the empirical model OkumuraHata-Rural are represented by a dash-dot line, it can be observed that Okumura-Hata model underestimates the PL values and presents a slower rising tendency; By contrast, the result of LITU-R model in dotted line shows smaller error since it was developed to follow data for higher dissipation. However, they all show relatively large deviations compared with our proposed models. So to evaluate the different path loss models thoroughly, we use three parameters: the RMSE, the Mean Absolute Error (MAE), and the Mean Absolute Percentage Error (MAPE). From Table 5, we can observe that the best prediction is achieved by using the proposed path loss model.

The primary cause is that none of the existing models could estimate the path loss at any height without any LAI or DBH. Furthermore, the value of RMSE, MAE, and MAPE in Okumura-Hata-Rural and LITU-R highly vary 


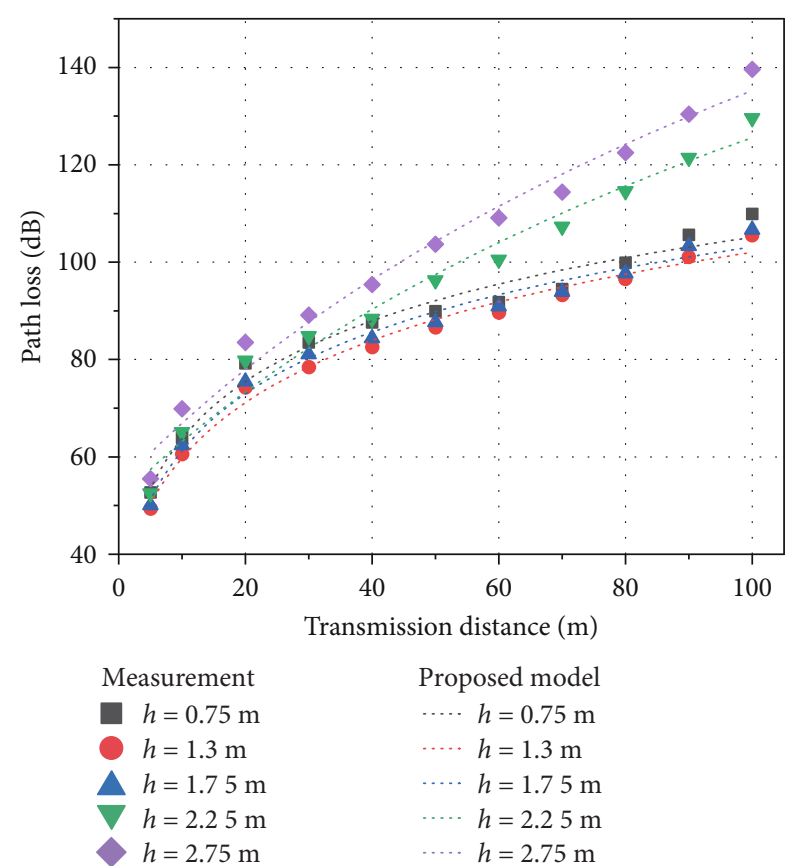

(a) $\mathrm{LAI}=0.67, \mathrm{DBH}=7.8$

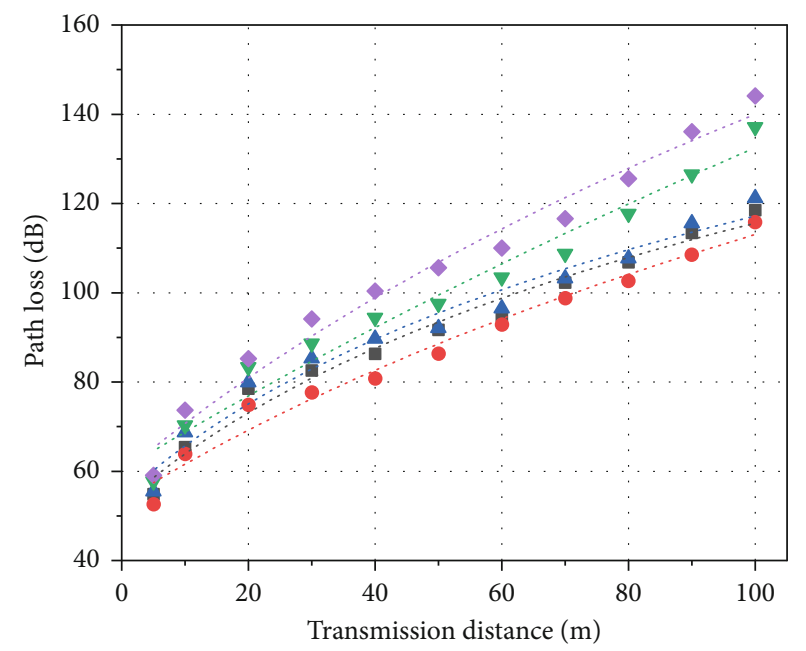

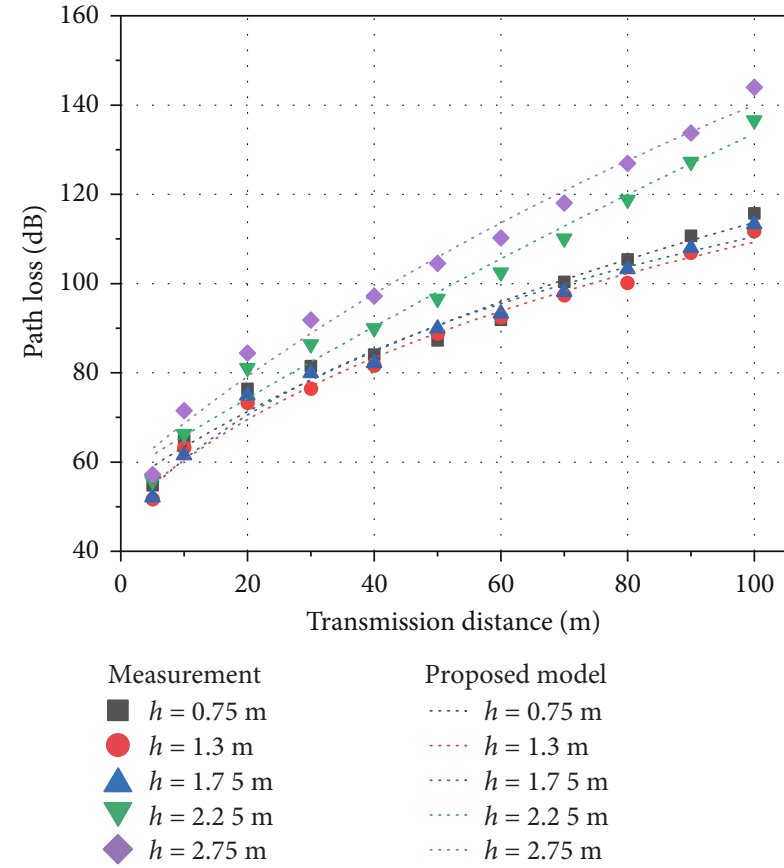

(b) $\mathrm{LAI}=1.44, \mathrm{DBH}=8.5$

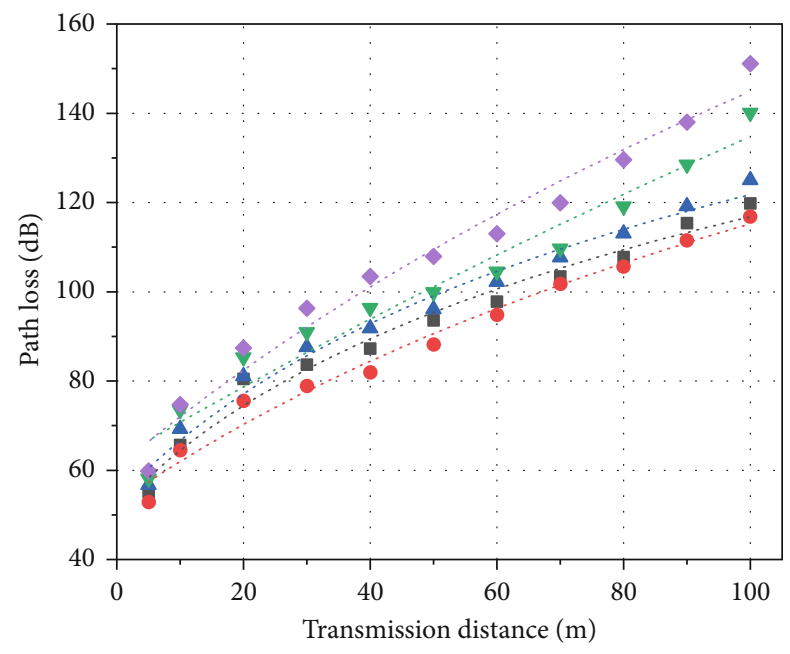

(c) $\mathrm{LAI}=2.02, \mathrm{DBH}=9.1$

(d) $\mathrm{LAI}=2.85, \mathrm{DBH}=12.4$

Figure 8: Continued. 

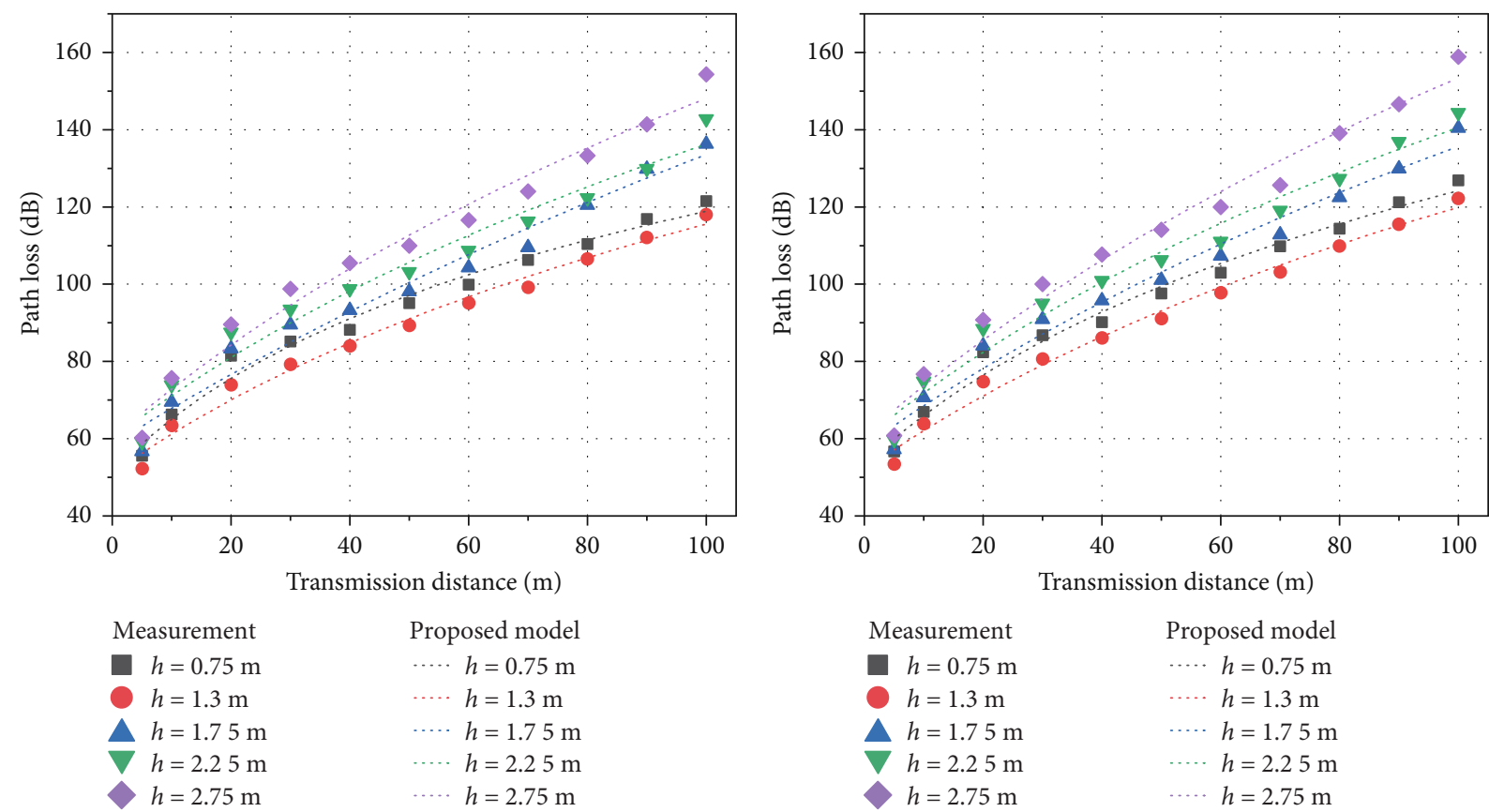

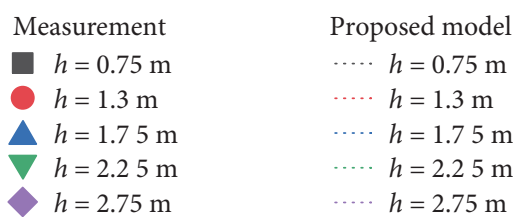

(e) $\mathrm{LAI}=3.56, \mathrm{DBH}=15.6$

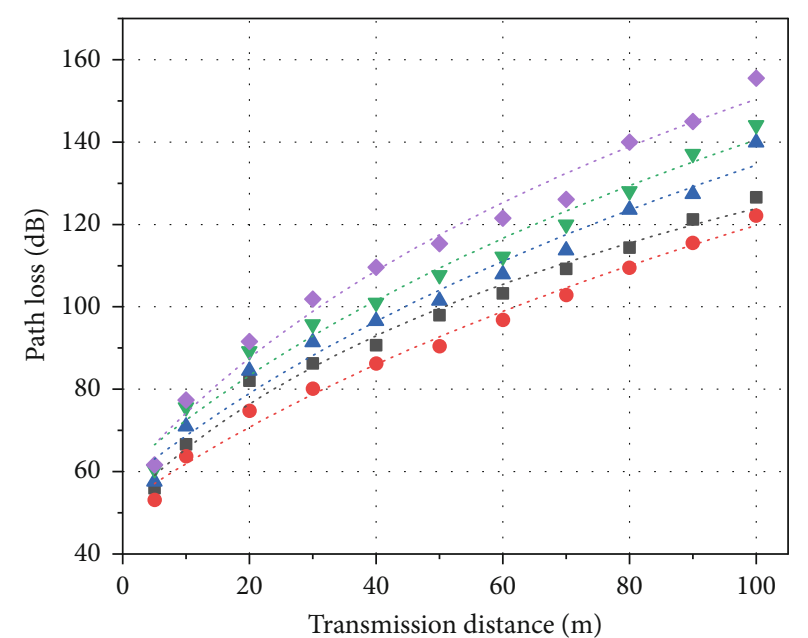

(g) $\mathrm{LAI}=5.16, \mathrm{DBH}=11.5$

(f) $\mathrm{LAI}=4.38, \mathrm{DBH}=12.8$

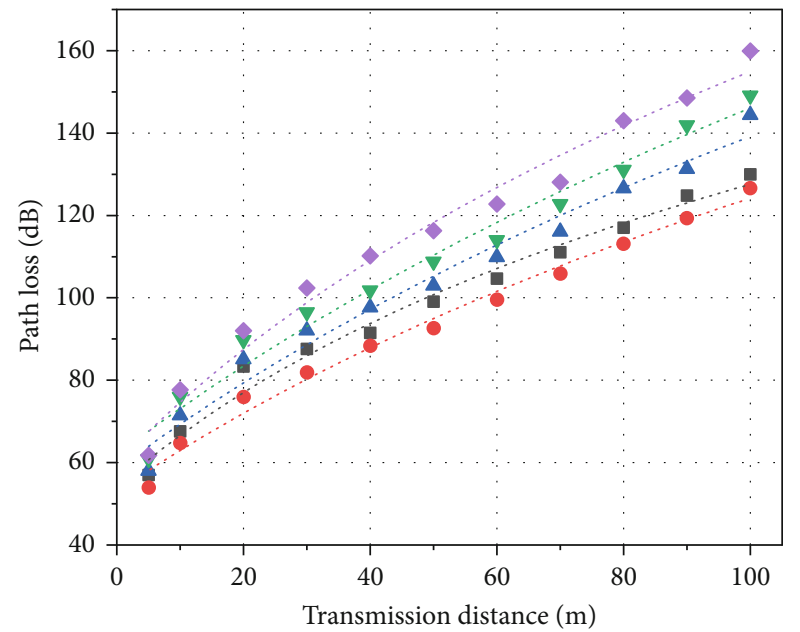

$$
\begin{aligned}
& \text { Measurement Proposed model } \\
& \text { - } h=0.75 \mathrm{~m} \\
& h=1.3 \mathrm{~m} \\
& h=1.75 \mathrm{~m} \\
& h=2.25 \mathrm{~m} \\
& h=2.75 \mathrm{~m}
\end{aligned}
$$

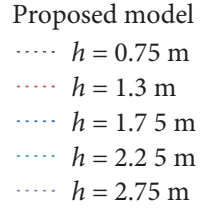

(h) $\mathrm{LAI}=5.23, \mathrm{DBH}=13.3$

Figure 8: Comparisons between the measurements and the new model at 8 selected points.

from one height to another, therefore, a slight variation of antenna or forestry parameters would negatively affect the prediction of the path loss in these models. Our proposed new model outperforms the existing models with the lowest RMSE, MAE, and MAPE regardless of the height of the antenna. Thus, the predicted values of our model are closer to real observations than the existing models.

4.2. Field Measurement on Energy-Harvesting LoRa Nodes. In this section, we evaluate the performance of the proposed radio propagation model based on the wind energy harvesting LoRaWAN which has been mounted in the sample mixed forest at Nanjing Forestry University [22]. We take the windpowered sensor nodes serving as transmitters (Figure 10 shows the node's mainboard, while the sensors could be attached on when in practice). An unlimited power supply sink is responsible for receiving messages and returning the packet delivery ratio (PDR) every day. The transmitting rate is $250 \mathrm{bps}$, and the payload length is 50 bytes. The selected nodes are located at 3 different positions: (i) $\mathrm{LAI}_{\mathrm{i}}=1.99$, 
TABLE 4: Validation results at different heights for 8 testing points.

\begin{tabular}{lcccccccc}
\hline Antenna height $(\mathrm{m})$ & $(\mathrm{a})$ & $(\mathrm{b})$ & $(\mathrm{c})$ & $(\mathrm{d})$ & $(\mathrm{e})$ & $(\mathrm{f})$ & $(\mathrm{g})$ & $(\mathrm{h})$ \\
\hline \multirow{2}{*}{0.75} & 0.93 & 0.91 & 0.88 & 0.95 & 0.93 & 0.90 & 0.94 & 0.96 \\
& 2.87 & 1.89 & 3.84 & 3.15 & 2.69 & 2.41 & 2.95 & 3.37 \\
1.3 & 0.96 & 0.96 & 0.84 & 0.93 & 0.87 & 0.86 & 0.91 & 0.95 \\
& 3.91 & 2.16 & 2.96 & 2.37 & 2.19 & 3.58 & 3.40 & 1.77 \\
1.75 & 0.94 & 0.93 & 0.95 & 0.96 & 0.90 & 0.92 & 0.88 & 0.99 \\
& 1.72 & 3.74 & 2.06 & 2.89 & 3.06 & 4.07 & 3.76 & 2.55 \\
2.25 & 0.92 & 0.90 & 0.97 & 0.94 & 0.95 & 0.97 & 0.85 & 0.97 \\
& 2.49 & 3.81 & 3.41 & 3.86 & 3.34 & 2.61 & 2.79 & 2.72 \\
2.75 & 0.88 & 0.89 & 0.85 & 0.87 & 0.91 & 0.93 & 0.82 & 0.84 \\
& 3.14 & 2.76 & 2.82 & 2.63 & 2.99 & 3.67 & 4.11 & 2.09 \\
\hline
\end{tabular}

*The first line denotes the $R^{2}$ values, and the second line indicates the RMSE values at each height.

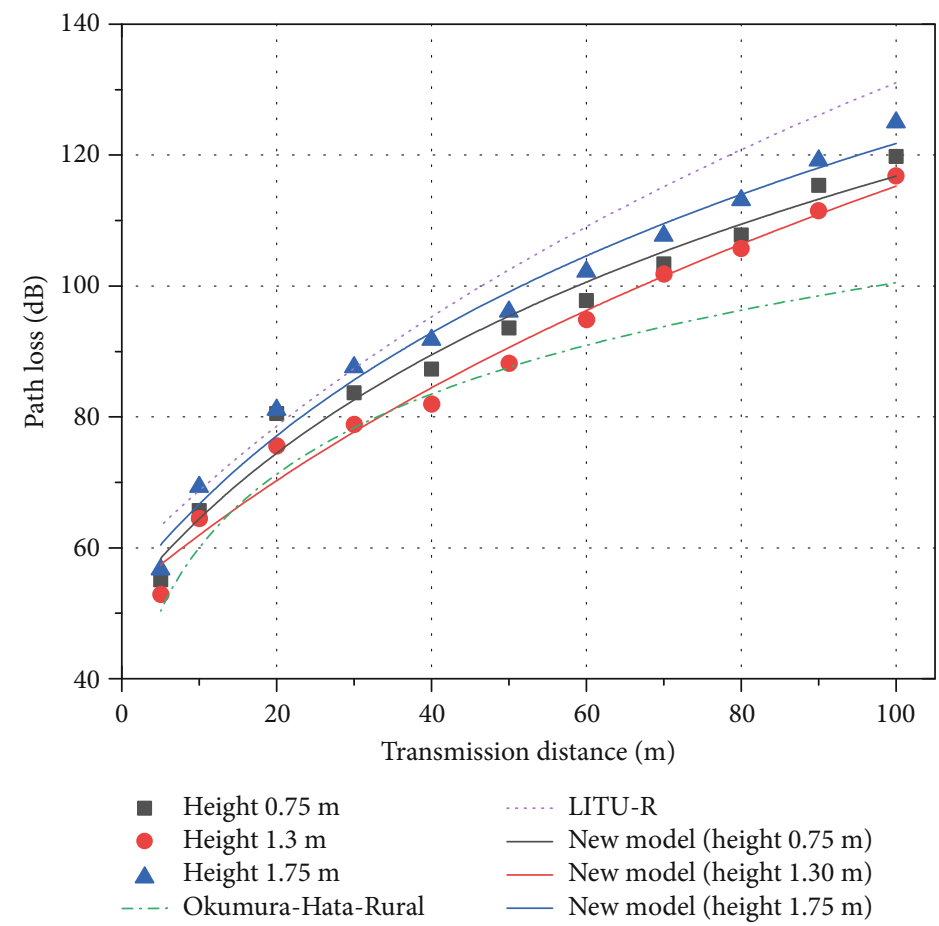

Figure 9: Comparisons between the new model and two existing models $(\mathrm{LAI}=2.85, \mathrm{DBH}=12.4)$.

TABle 5: The RMSE, MAE, and MAPE values between the proposed model and existing models.

\begin{tabular}{|c|c|c|c|c|c|c|c|c|c|}
\hline \multirow{2}{*}{ Location } & \multicolumn{3}{|c|}{ Okumura-Hata-rural } & \multicolumn{3}{|c|}{ LITU-R } & \multicolumn{3}{|c|}{ Proposed model } \\
\hline & RMSE & MAE & MAPE (\%) & RMSE & MAE & MAPE (\%) & RMSE & MAE & MAPE (\%) \\
\hline Height $0.75 \mathrm{~m}$ & 11.66 & 10.17 & 10.70 & 8.84 & 7.03 & 8.11 & 3.15 & 2.79 & 2.96 \\
\hline Height $1.30 \mathrm{~m}$ & 9.78 & 8.56 & 9.44 & 6.93 & 5.49 & 5.87 & 2.37 & 1.96 & 2.17 \\
\hline Height $1.75 \mathrm{~m}$ & 15.41 & 13.79 & 14.12 & 13.35 & 11.24 & 12.63 & 2.89 & 2.02 & 2.79 \\
\hline
\end{tabular}

$\mathrm{DBH}_{\mathrm{i}}=13.82$; (ii) $\mathrm{LAI}_{\mathrm{ii}}=3.01, \mathrm{DBH}_{\mathrm{ii}}=10.78$; (iii) $\mathrm{LAI}_{\mathrm{iii}}=$ 2.63, $\mathrm{DBH}_{\mathrm{iii}}=15.84$. The corresponding communication distances and antenna heights are (i) $d_{i}=37 \mathrm{~m}, h_{i}=1.0 \mathrm{~m}$; (ii) $d_{i i}=55 \mathrm{~m}, h_{i i}=1.3 \mathrm{~m}$; (iii) $d_{i i i}=64 \mathrm{~m}, h_{i i i}=2.0 \mathrm{~m}$.

We validate the effectiveness of our propagation loss calculation module by using two comparisons. The existing fixed transmission power scheme is implemented as a reference, which is referred to as the Fixed-TX scheme. One of the wind-harvesting LoRaWAN nodes works under our proposed model at position (iii), while the other nodes located at positions (i) and (ii) be set with the fixed transmission power $\mathrm{TX}=7 \mathrm{dBm}$ and $\mathrm{TX}=14 \mathrm{dBm}$, respectively. The node (iii) 


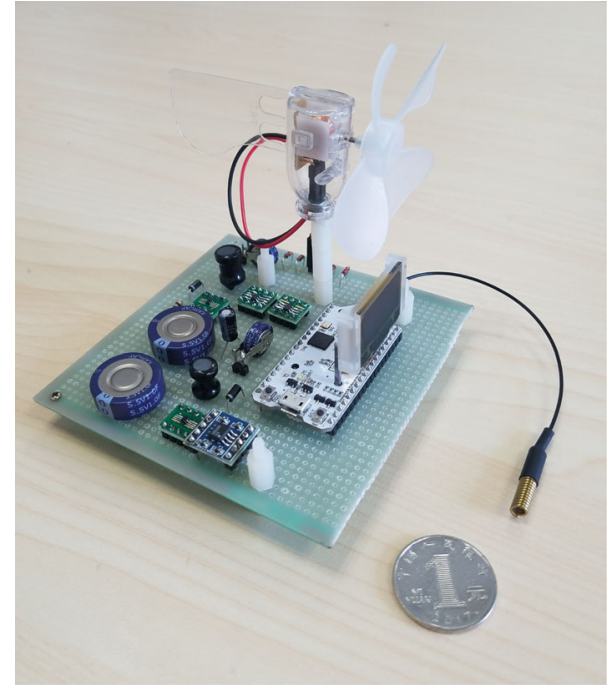

FIgURE 10: Wind energy harvesting LoRa node (mainboard).

could compute its transmitting power by equation (1) based on the RSSI value efficiently. All three nodes start with an initial energy of 1 Joule, and the average wind speed during the experiment is $4.4 \mathrm{~m} / \mathrm{s}$.

Table 6 presents the average PDR of total of 10,080 packets (ten packets per minute during 7 days) and the residual energy of three nodes in the final time. We can see that the proposed method achieves the lowest energy consumption compared with the other transmission power strategies no matter the distance. Compared with the Fixed-TX$14 \mathrm{dBm}$ scheme, our proposed module achieves energy reduction around 30\%. Compared with the Fixed-TX$7 \mathrm{dBm}$ scheme, our proposed module improves the PDR around 5\%. The wireless path loss and the background noise are always time-varying, the fixed transmission power definitely cannot guarantee the optimal transmission energy efficiency. The proposed PL model is effective in dynamically calculating the optimal transmission power along with the lowest energy cost.

4.3. Rain Attenuation of LoRaWAN in the Forest. Rain and fog is quite common in the forestry district. Many studies indicate that the propagation of the radio signal is affected by rain and there are some remarkable models deduced to analyze its influence [30, 31]. However, most existing researches focus on the rain attenuation by wireless signals with frequencies above $10 \mathrm{GHz}$. So in this part, we investigate the influence of rain attenuation within the proposed forestry LoRaWAN for the first time. The experiment setup is just the same as part 4.2 and we record the variations of RSSI in position (ii) every 10 seconds when rainfall comes. The measurement data presented in Figure 11 are filtered by a moving average window with 30 samples. It is noticeable that during rainfall periods there is an obvious attenuation of PL.

Figure 11(a) shows a significant impact on path loss of LoRa signal when it is rainy during a 7-day consecutive observation, every increasement of PL values corresponds to a rainfall event accurately. Although the rain rate which has been recorded by a standard rain gauge [32] does not exceed the extremely heavy level, a nearly $8 \mathrm{~dB}$ variation of PL has occurred. Figure 11(b) shows a detailed changing process of rain attenuation, PL value increases sharply when the rain begins to fall, and it returns to the original state relatively slow after the rain stops. The main reason of fading may be the water molecular which is adhered on the antenna of LoRa nodes and pervaded in the transmission space, it would change the propagation characteristic and the antenna property drastically.

According to reference [33], the rain attenuation can be represented by $a R_{P}^{b}$, where $R_{P}$ is the rain rate with a given period $P$ while $a$ and $b$ are depending on the radio wave frequency and the rain temperature. Hence, we calculate this item with the collected rainy data and deduce the result as $R_{P}$ is set to $3.86 \mathrm{~mm} / \mathrm{hr}$ based on the conventional rain information from local weather station, $a$ and $b$ just are 2.11 and 0.55 , respectively. So the updated general PL model would be:

$$
\mathrm{PL}_{\mathrm{LN}}(\mathrm{dB})=\mathrm{PL}\left(d_{0}\right)+10 n \log _{10}\left(\frac{d}{d_{0}}\right)+X_{\sigma}+a R_{p}^{b}
$$

Furthermore, we also apply the updated model on the wind-harvesting LoRaWAN node to verify its effectiveness. It is located in position (iii) as well and the average wind speed is $4.9 \mathrm{~m} / \mathrm{s}$ during the rainy period. The other two nodes located at positions (i) and (ii) are set the same as part 4.2, and the corresponding results are shown in Table 7.

It can be seen that the residual energy of the updated model decreases slightly otherwise the two Fixed-TX nodes get higher due to the larger wind speed. However, PDR of the updated scheme keeps $100 \%$, while the comparative two nodes drop significantly. This indicates that the updated PL model matches the real rain attenuation efficiently and works stably in energy neutral mechanism.

\section{Conclusion}

IoT in forest environments can support applications such as fire alarm, environment surveillance, pest diagnosis, and tree growth monitoring. Large-scale deployment of LoRaWAN in forest environments requires accurate characterization of the propagation channel utilizing practical sensor nodes. However, most of the existing studies in forest environments use signal generators instead of practical sensor nodes, which, in turn, may lead to inaccurate models and, as a result, poor decision making during large-scale deployment of LoRa nodes. Inaccurate models may also result in the poor energy efficiency of the network as well as inaccuracy in localization and coverage control applications.

In this work, empirical path loss models for LoRaWAN in the mixed forest of Eastern China are researched using practical sensor node measurements at $433 \mathrm{MHz}$. New proposed model based on the DBH and LAI with different heights is developed and compared with the existing 
TABLE 6: The residual energy and PDR of three nodes.

\begin{tabular}{lccc}
\hline Average testing result & Proposed PL model & Fixed-TX-14 dBm & Fixed-TX-7 dBm \\
\hline Supercapacitor voltage (volt, residual energy) & 3.194 & 2.372 & 2.468 \\
PDR (\%) & 100 & 97 & 95 \\
\hline
\end{tabular}

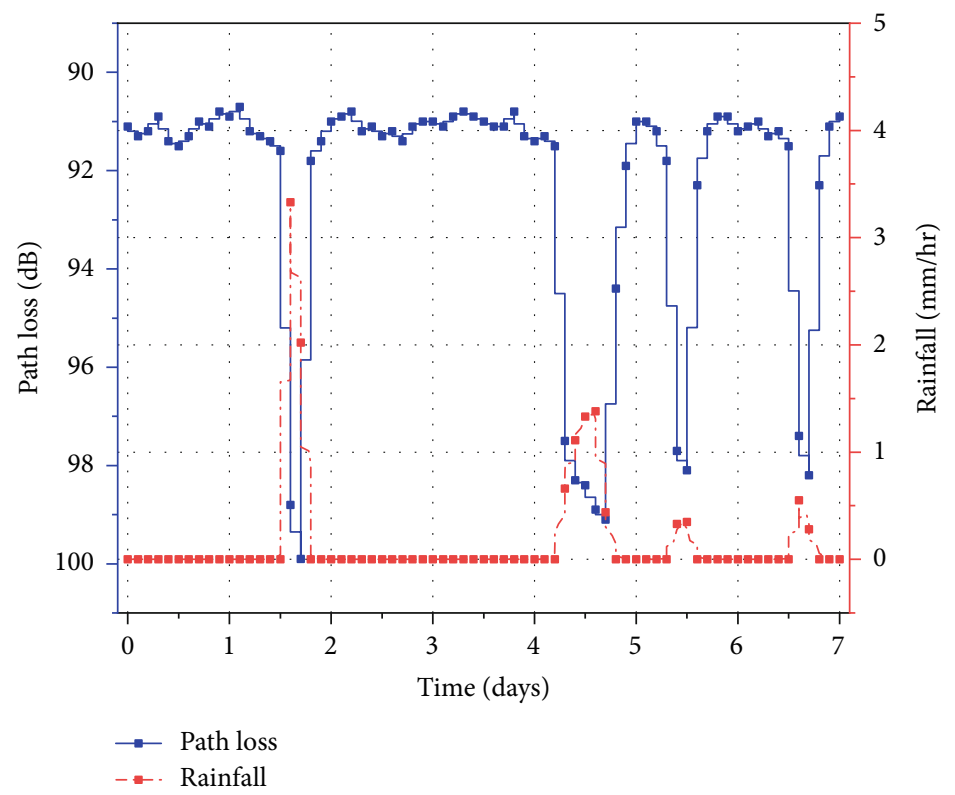

(a)

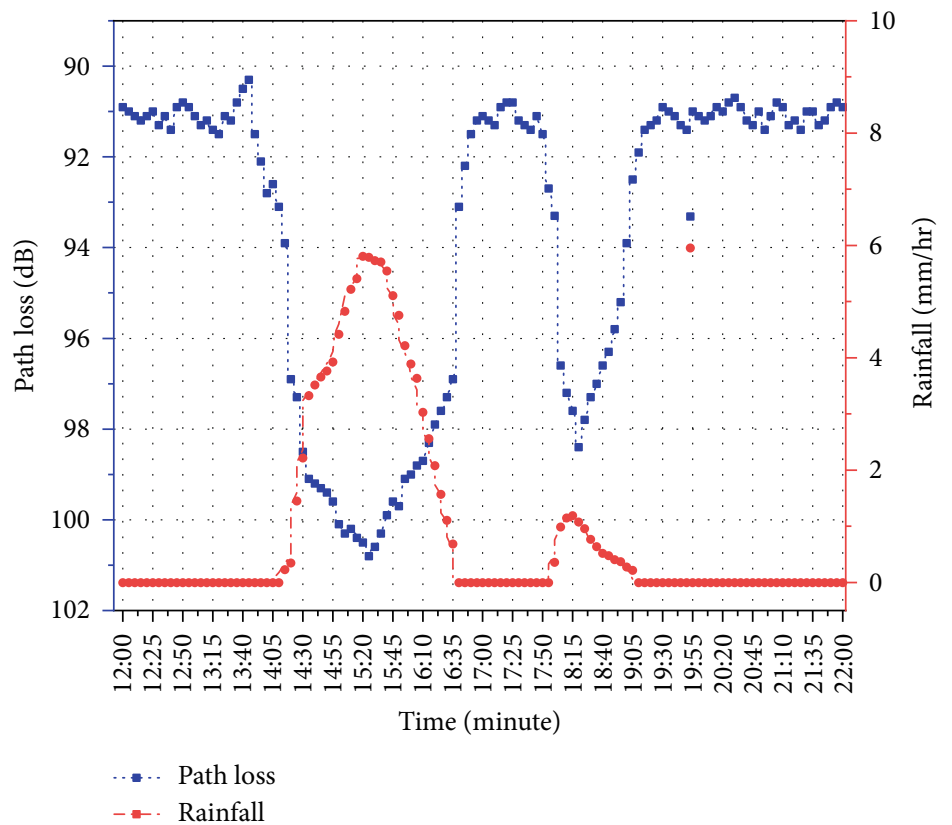

(b)

FIgURE 11: Variation of RSSI vs. rainfall in position (ii) from 2019.05.01 to 2019.05.08.

Okumura-Hata-Rural model and LITU-R path loss models to demonstrate its accuracy. Moreover, the performance of wind energy harvesting based LoRa nodes equipped with our model has also been investigated. Results show that the
RMSE, MAE, and MAPE values of the new model were almost all smaller than the existing models, thus the proposed model best matches the real field application status of LoRaWAN in mixed forest. 
TABLE 7: The residual energy and PDR of three nodes during rainy time.

\begin{tabular}{lccc}
\hline Average testing result & Proposed PL model & Fixed-TX-14 dBm & Fixed-TX-7 dBm \\
\hline Supercapacitor voltage (volt, residual energy) & 3.031 & 2.447 & 2.584 \\
PDR (\%) & 100 & 93 & 90 \\
\hline
\end{tabular}

The measured data, as well as the proposed models, can be useful for efficient planning and deployment of LoRaWAN in forest environments, even during the rainy season. In addition, a future study will include using the same approach to investigate the behavior of other LPWAN protocols like LTE-M and NB-IoT in forest environments.

\section{Data Availability}

The data used to support the findings of this study are included within the article.

\section{Conflicts of Interest}

The authors declare that they have no conflicts of interest.

\section{Acknowledgments}

This study was financially supported by the National Natural Science Foundation of China under Grants 31700478 and 31670554.

\section{References}

[1] H. Xiang, L. Zhang, and D. Wen, "Change of soil carbon fractions and water-stable aggregates in a Forest ecosystem succession in South China," Forests, vol. 6, no. 12, pp. 2703-2718, 2015.

[2] J. Dempewolf, J. Nagol, S. Hein, C. Thiel, and R. Zimmermann, "Measurement of within-season tree height growth in a mixed Forest stand using UAV imagery," Forests, vol. 8, no. 7, p. 231, 2017.

[3] P. Surový and K. Kuželka, “Acquisition of forest attributes for decision support at the forest enterprise level using remotesensing techniques-a review," Forests, vol. 10, no. 3, p. 273, 2019.

[4] W. Ayoub, A. E. Samhat, F. Nouvel, M. Mroue, and J.C. Prevotet, "Internet of mobile things: overview of LoRaWAN, DASH7, and NB-IoT in LPWANs standards and supported mobility," IEEE Communications Surveys \& Tutorials, vol. 21, no. 2, pp. 1561-1581, 2019.

[5] M. Rady, M. Hafeez, and S. A. Raza Zaidi, "Computational methods for network-aware and network-agnostic IoT low power wide area networks (LPWANs)," IEEE Internet of Things Journal, vol. 6, no. 3, pp. 5732-5744, 2019.

[6] M. Chen, Y. Miao, X. Jian, X. Wang, and I. Humar, "CognitiveLPWAN: towards intelligent wireless services in hybrid low power wide area networks," IEEE Transactions on Green Communications and Networking, vol. 3, no. 2, pp. 409-417, 2019.

[7] T. O. Olasupo and C. E. Otero, "The impacts of node orientation on radio propagation models for airborne-deployed sensor networks in large-scale tree vegetation terrains," IEEE Transactions on Systems, Man, and Cybernetics: Systems, vol. 50, no. 1, pp. 256-269, 2020.
[8] S. Sendra, L. García, J. Lloret, I. Bosch, and R. Vega-Rodríguez, "LoRaWAN network for fire monitoring in rural environments," Electronics, vol. 9, no. 3, p. 531, 2020.

[9] P. Avila-Campos, F. Astudillo-Salinas, A. Vazquez-Rodas, and A. Araujo, "Evaluation of LoRaWAN transmission range for wireless sensor networks in riparian forests," in Proceedings of the 22nd International ACM Conference on Modeling, Analysis and Simulation of Wireless and Mobile Systems - MSWIM '19, pp. 199-206, Miami Beach, FL, USA, November 2019.

[10] O. Iova, A. L. Murphy, G. P. Picco et al., "LoRa from the city to the mountains: exploration of hardware and environmental factors," in Proceedings of the 2017 International conference on embedded wireless systems and networks, pp. 317-322, Uppsala, Sweden, February 2017.

[11] Y. S. Meng, Y. H. Lee, and B. C. Ng, "Empirical near ground path loss modeling in a forest at VHF and UHF bands," IEEE Transactions on Antennas and Propagation, vol. 57, no. 5, pp. 1461-1468, 2009.

[12] J. A. R. Azevedo and F. E. S. Santos, "An empirical propagation model for forest environments at tree trunk level," IEEE Transactions on Antennas and Propagation, vol. 59, no. 6, pp. 23572367, 2011.

[13] C. R. Anderson, H. I. Volos, and R. M. Buehrer, "Characterization of low-antenna ultra-wideband propagation in a forest environment," IEEE Transactions on Vehicular Technology, vol. 62, no. 7, pp. 2878-2895, 2013.

[14] A. Palaios, Y. Labou, and P. Mähönen, “A study on the forest radio propagation characteristics in European mixed forest environment," in 2014 IEEE Military Communications Conference, pp. 376-381, Baltimore, MD, USA, October 2014.

[15] S. Benaissa, D. Plets, E. Tanghe et al., "Internet of animals: characterisation of LoRa sub-GHz off-body wireless channel in dairy barns," Electronics Letters, vol. 53, no. 18, pp. 12811283, 2017.

[16] S. Hosseinzadeh, H. Larijani, K. Curtis, A. Wixted, and A. Amini, "Empirical propagation performance evaluation of LoRa for indoor environment," in 2017 IEEE 15th International Conference on Industrial Informatics (INDIN), pp. 2631, Emden, Germany, July 2017.

[17] R. El Chall, S. Lahoud, and M. El Helou, "LoRaWAN network: radio propagation models and performance evaluation in various environments in Lebanon," IEEE Internet of Things Journal, vol. 6, no. 2, pp. 2366-2378, 2019.

[18] R. Sanchez-Iborra, J. Sanchez-Gomez, J. Ballesta-Viñas, M.D. Cano, and A. Skarmeta, "Performance evaluation of LoRa considering scenario conditions," Sensors, vol. 18, no. 3, p. 772, 2018.

[19] G. Callebaut and L. Van der Perre, "Characterization of LoRa point-to-point path loss: measurement campaigns and modeling considering censored data," IEEE Internet of Things Journal, vol. 7, no. 3, pp. 1910-1918, 2020.

[20] M. S. Sardar, Y. Yi, W. Xue-fen et al., "Experimental analysis of LoRa CSS wireless transmission characteristics for forestry monitoring and sensing," in 2018 International Symposium 
in Sensing and Instrumentation in IoT Era (ISSI), pp. 0124901254, Shanghai, China, September 2018.

[21] Y. Wu, B. Li, Y. Zhu, and W. Liu, "Energy-neutral communication protocol for living-tree bioenergy-powered wireless sensor network," Mobile Information Systems, vol. 2018, Article ID 5294026, 15 pages, 2018.

[22] Y. Wu, B. Li, and F. Zhang, "Predictive power management for wind powered wireless sensor node," Future Internet, vol. 10, no. 9, p. 85, 2018.

[23] D. Gao, S. Zhang, F. Zhang, T. He, and J. Zhang, "RowBee: a routing protocol based on cross-technology communication for energy-harvesting wireless sensor networks," IEEE Access, vol. 7, pp. 40663-40673, 2019.

[24] Y. Okumura, E. Ohmori, T. Kawano, and K. Fukuda, "Field strength and its variability in VHF and UHF land mobile radio service," Review of the Electrical Communication Laboratory, vol. 16, no. 9-10, pp. 825-873, 1968.

[25] T. O. Olasupo, "Wireless communication modeling for the deployment of tiny IoT devices in rocky and mountainous environments," IEEE Sensors Letters, vol. 3, no. 7, pp. 1-4, 2019.

[26] S. Gao, X. Zhang, C. du, and Q. Ji, “A multichannel low-power wide-area network with high-accuracy synchronization ability for machine vibration monitoring," IEEE Internet of Things Journal, vol. 6, no. 3, pp. 5040-5047, 2019.

[27] J. Bauer, B. Siegmann, T. Jarmer, and N. Aschenbruck, "On the potential of wireless sensor networks for the in-situ assessment of crop leaf area index," IEEE Sensors Letters, vol. 128, pp. 149159, 2016.

[28] Y. Qu, J. Meng, H. Wan, and Y. Li, "Preliminary study on integrated wireless smart terminals for leaf area index measurement," Computers and Electronics in Agriculture, vol. 129, pp. 56-65, 2016.

[29] Y. Hong, N. Heerink, S. Jin, P. Berentsen, L. Zhang, and W. van der Werf, "Intercropping and agroforestry in China Current state and trends," Agriculture, Ecosystems \& Environment, vol. 244, no. 15, pp. 52-61, 2017.

[30] S.-H. Fang, Y.-C. Cheng, and Y.-R. Chien, "Exploiting sensed radio strength and precipitation for improved distance estimation," IEEE Sensors Journal, vol. 18, no. 16, pp. 6863-6873, 2018.

[31] M. Cheffena and M. Mohamed, "Empirical path loss models for wireless sensor network deployment in snowy environments," IEEE Antennas and Wireless Propagation Letters, vol. 16, pp. 2877-2880, 2017.

[32] “TS RMS 1000Tsingsense Co., Beijing, ChinaMay 2020, http:// www.tsingsense.com.cn/index.php?act=goods\&op= index\&goods_id $=100076$.

[33] R. Olsen, D. Rogers, and D. Hodge, "The $\mathrm{aR}^{\mathrm{b}}$ relation in the calculation of rain attenuation," IEEE Transactions on Antennas and Propagation, vol. 26, no. 2, pp. 318-329, 1978. 